\title{
The gastric caeca of pentatomids as a house for actinomycetes
}

Tiago D Zucchi ${ }^{1,2^{*}}$, Simone S Prado ${ }^{2,3}$ and Fernando L Cônsoli ${ }^{2 *}$

\begin{abstract}
Background: Microbes are extensively associated with insects, playing key roles in insect defense, nutrition and reproduction. Most of the associations reported involve Proteobacteria. Despite the fact that Actinobacteria associated with insects were shown to produce antibiotic barriers against pathogens to the hosts or to their food and nutrients, there are few studies focusing on their association with insects. Thus, we surveyed the Actinobacteria diversity on a specific region of the midgut of seven species of stinkbugs (Hemiptera: Pentatomidae) known to carry a diversity of symbiotically-associated Proteobacteria.

Results: A total of 34 phylotypes were placed in 11 different Actinobacteria families. Dichelops melacanthus held the highest diversity with six actinobacteria families represented by nine phylotypes. Thyanta perditor $(n=7)$, Edessa meditabunda $(n=5)$, Loxa deducta $(n=4)$ and Pellaea stictica $(n=3)$ were all associated with three families. Piezodorus guildini $(n=3)$ and Nezara viridula $(n=3)$ had the lowest diversity, being associated with two (Propionibacteriaceae and Mycobacteriaceae) and one (Streptomyceataceae) families, respectively. Corynebacteriaceae and Mycobacteriaceae were the most common families with phylotypes from three different insect species each one.

Conclusions: Many phylotypes shared a low 16S rRNA gene similarity with their closest type strains and formed new phyletic lines on the periphery of several genera. This is a strong indicative that stinkbug caeca can harbor new species of actinobacteria, which might be derived from specific associations with the species of stinkbugs studied. Although the well-known role of actinobacteria as a source of biomolecules, the ecological features of these symbionts on the stinkbugs biology remain unknown.
\end{abstract}

Keywords: Actinobacteria, Bacterial diversity, Pentatomidae, Symbiosis

\section{Background}

Insects are by far the most diverse and largest cosmopolitan group of existing living animals with over a million described species [1,2]. Their successful worldwide dissemination was largely influenced by their associations with microbes (mostly bacteria), which allowed insects to exploit nutritionally-deficient food sources, either by complementing the diet with essential nutrients (e.g., Buchnera aphidicola in aphids) [3] and/or aiding in food digestion (bacteria and protozoa in termites) [4]. However, some associations are not beneficial to the host and the bacteria can play a pathogenic role affecting the host fitness (reduced

\footnotetext{
* Correspondence: tiago_zucchi@hotmail.com; fconsoli@usp.br

'Lab de Microbiologia Ambiental, EMBRAPA Meio Ambiente, Rodovia SP 340, Km 127,5, CP 69, 13820-000, Jaguariúna, SP, Brazil

${ }^{2}$ Lab de Interações em Insetos, Depto de Entomologia \& Acarologia, Escola Superior de Agricultura "Luiz de Queiroz", Universidade de São Paulo (ESALQ/USP), Av Pádua Dias 11, CP 9, 13418-900, Piracicaba, SP, Brazil Full list of author information is available at the end of the article
}

reproduction and longevity, and increased mortality) [5]. The interactions insect-microorganism had been mostly investigated focusing on entomopathogens (virus, bacteria and fungi), but the limitations to the study of secondary and primary symbionts due to the difficulties to culture them in vitro have been recently overcome. The development of molecular tools and the use of new technologies for metabolite analysis are allowing for in depth investigations on the interactions bacteria and insects develop [6,7].

Bacterial mutualists have been firstly studied for their ecological appeal on insect development, but have recently gained a lot of attention due to their exploitation for insect and/or insect-vectored disease control, either through their direct elimination [8] or paratransgenesis [9]. Although the promising advances which may arise by these techniques, the use of the most intrinsic association between insects and bacteria, i.e. obligatory endocellular symbionts, is still thoroughly untapped mainly 
because these symbionts are difficult to cultivate or are not cultivable yet, which implies on an extra effort to obtain positive results. On the other hand, secondary symbionts are relatively straight forward to isolate and may therefore become a breakthrough tool on biological control of insect pests. However, most of these bacteria establish loosen relationships with their hosts and efforts must be driven to identify the most persistent secondary symbiont species which colonize the insect.

Stinkbugs (Hemiptera: Pentatomidae) are widely distributed around the globe and many species are considered as agricultural pests. A particular region of their midgut, the gastric caeca, has been scrutinized due to its association with a community of bacteria and the possible role this microbiota may have on host nutrition [10]. Several pentatomid species had their midgut symbionts investigated by culture-independent approaches and the most abundant bacterial species were identified as belonging to the Enterobacteriaceae [11-13]. However, these studies have used universal primers and PCR conditions that would favor this particular group of bacteria, while bacteria that would require particular PCR conditions for successful amplification would not be detected or be a minor representative in the population of amplicons produced. These bacteria could also be key players in the process of symbiosis and have an important impact in host fitness.

Our observations of scanning electron micrograph images of the gastric caeca of species of stinkbugs indicated the existence of cells with a morphology that resembled that of Actinobacteria (data not shown). Actinobacteria are known to not amplify well in PCR conditions normally used employing the universal primers developed based on Escherichia coli, and it has already been reported associated with the gut of several orders of insects [14-17], including a couple of species belonging to Hemiptera-Heteroptera $[18,19]$. Despite the existent data on the nutritional contribution of gutassociated Actinobacteria [18], and the provision of an antibiotic-barrier against pathogens by actinobacteria associated with the host body surface [20,21], little is known on the diversity of Actinobacteria associated with the gut of insects [22].

Therefore, due to the lack of information on the actinobacterial diversity associated with the gut of stinkbugs, we aimed to characterize the actinobacteria communities inhabiting the gastric caeca of the pentatomids Dichelops melacanthus, Edessa meditabunda, Loxa deducta, Nezara viridula, Pellaea stictica, Piezodorus guildinii and Thyanta perditor, by using a culture independent approach.

\section{Results}

The diversity of Actinobacteria associated with the V4 region of the midgut was quite different depending on the stinkbug species. Dichelops melacanthus, T. perditor and $E$. meditabunda had a quite diverse actinoflora associated, with several genera from different families of Actinobacteria. On the other hand, the actinoflora of $N$. viridula and P. guildinii were represented by one genus or a couple of genera from two distinct families, respectively (Table 1, Figure 1). Database search for sequence similarities to type strains ranged from 92.5 to $100 \%$ sequence identity (Table 1). In general, there is not a major, predominant phylotype within each stinkbug species. But Mycobacteriaceae are the most frequent whenever they occur (Table 1), with the exception of the phylotype of Mycobacteriaceae in P. stictica, which was almost as frequent as the others phylotypes.

The phylogenetic analysis of the 16S rRNA gene placed all the 34 phylotypes from stinkbugs within the Actinomycetales order (Figure 1). In general, the analysis was suffice to determine the family of the phylotypes and 25 of them were distributed into 10 families: Corynebacteriaceae $(n=5$ phylotypes); Micrococcaceae, Mycobacteriaceae, Propionibacteriaceae and Streptomycetaceae ( $n=3$ phylotypes each); Actinomycetaceae, Brevibacteriaceae and Intransporangiaceae ( $n=2$ phylotypes each); Kineosporiaceae and Microbacteriaceae ( $n=1$ phylotype each) (Figure 1). However, our results demonstrated that phylotypes which shared a $16 \mathrm{~S}$ rRNA gene similarity value lower than $96.0 \%$ with their nearest type strain, although strongly associated with families included in the order Actinomycetales, formed new phyletic lines on the periphery of 16S rRNA gene subclade of known actinobacteria families. Therefore, it was not possible to assign them into a specific family. This was the case of IIL-cDm-9s1 which grouped together with other four phylotypes and formed a new 16S rRNA gene subclade closely associated with the subclade represented by sequences of the 16S rRNA gene of Dietziaceae. The two subclades were supported by all tree-making algorithms and by a bootstrap value of $56 \%$. Similarly, the IIL-cDm9s3, IIL-cLd-3s5 and IIL-cTp-5s10 phylotypes formed new phyletic lines strongly associated with Micrococcaceae, Mycobacteriaceae and Actinomycetaceae 16S rRNA gene subclades, respectively, with bootstrap supporting values from $56 \%$ to $99 \%$. Furthermore, the highest phylotype diversity found for $D$. melacanthus was also represented by a high number of Actinomycetales families as this insect was associated with actinobacteria representatives scattered into five families and two other unresolved families (Figure 1). Similarly, the actinobacteria phylotypes from $T$. perditor were distributed into three families and one unresolved family, whereas E. meditabunda and P. guildinii had representatives within three and two families, respectively. Loxa deducta and P. stictica have actinobacteria representatives distributed into two families and one unresolved family. On the other hand, all phylotypes associated with $N$. viridula were comprised into a single family, Streptomycetacea. 
Table 1 Nearest matches of 16S rRNA sequences ( 640 bp long) of selected genotypes gut-associated actinobacteria from Pentatomidae

\begin{tabular}{|c|c|c|c|c|}
\hline \multirow[t]{2}{*}{ Amplified from } & \multirow[t]{2}{*}{ Clones } & \multicolumn{2}{|l|}{ Similarity with type-strain } & \multirow{2}{*}{$\begin{array}{l}\% \\
\text { phylotype }\end{array}$} \\
\hline & & Nearest match & Identity (\%) & \\
\hline \multirow[t]{9}{*}{ Dichelops melacanthus } & IIL-cDm-9s1 & Dietzia maris DSM $43672^{\top}$ (X79290) & 93.9 & 26.7 \\
\hline & IIL-cDm-9s2 & Propionibacterium granulosum DSM $20700^{\top}$ (AJ003057) & 99.2 & 13.3 \\
\hline & IIL-cDm-9s3 & Citricoccus parietis 02-Je-010 (FM992367) & 96.0 & 13.3 \\
\hline & IIL-cDm-9s4 & Citricoccus parietis 02-Je-010 ${ }^{\top}$ (FM992367) & 98.4 & 6.7 \\
\hline & IIL-cDm-9s9 & Corynebacterium durum IBS G1503T (Z97069) & 97.2 & 6.7 \\
\hline & IIL-cDm-9s23 & Dietzia timorensis ID05-A0528 ${ }^{\top}$ (AB377289) & 95.5 & 6.7 \\
\hline & IIL-cDm-9s24 & Brevibacterium permense VKM Ac-2280 (AY243343) & 99.5 & 6.7 \\
\hline & IIL-cDm-9s26 & Brevibacterium permense VKM Ac-2280 (AY243343) & 99.5 & 13.3 \\
\hline & IIL-cDm-9s27 & Kineococcus marinus KST3-3 $3^{\top}$ (DQ200982) & 98.8 & 6.7 \\
\hline \multirow[t]{5}{*}{ Edessa meditabunda } & IIL-cEm-14s4 & Corynebacterium freiburgense $1045^{\top}$ (FJ157329) & 97.3 & 6.3 \\
\hline & IIL-cEm-14s8 & Pseudoclavibacter chungangensis CAU59'(FJ514934) & 96.7 & 31.3 \\
\hline & IIL-cEm-14s9 & Citricoccus parietis 02-Je-010 (FM992367) & 98.8 & 25.0 \\
\hline & IIL-CEm-14s10 & Corynebacterium variabile DSM $20132^{\top}$ (AJ222815) & 98.3 & 25.0 \\
\hline & IIL-cEm-14s21 & Arthrobacter protophormiae DSM $20168^{\top}$ (X80745) & 99.8 & 12.5 \\
\hline \multirow[t]{4}{*}{ Loxa deducta } & IIL-cLd-3s2 & Dietzia timorensis ID05-A0528T (AB377289) & 95.9 & 37.5 \\
\hline & IIL-cLd-3s5 & Mycobacterium Ilatzerense MG13T (AJ746070) & 95.6 & 50.0 \\
\hline & $\| \mathrm{IL}-\mathrm{CLd}-3 \mathrm{~s} 10$ & Dietzia timorensis ID05-A0528 (AB377289) & 95.5 & 6.3 \\
\hline & IIL-CLd-3s21 & Ornithinimicrobium kibberense K22-20 (AY636111) & 97.3 & 6.3 \\
\hline \multirow[t]{3}{*}{ Nezara viridula } & IIL-cNv-20s10 & Streptomyces puniceus NBRC $12811^{\top}$ (AB184163) & 100.0 & 20.0 \\
\hline & IIL-cNv-20s17 & Streptomyces violascens ISP $5183^{\top}$ (AY999737) & 99.8 & 27.5 \\
\hline & IIL-cNv-20s19 & Streptomyces puniceus NBRC $12811^{\top}$ (AB184163) & 98.4 & 52.5 \\
\hline \multirow[t]{3}{*}{ Pellaea stictica } & IIL-cPs-1s22 & Mycobacterium phocaicum CIP $108542^{\top}$ (AY859682) & 99.2 & 25.0 \\
\hline & IIL-CPs-1s25 & Ornithinimicrobium kibberense K22-20 (AY636111) & 96.5 & 37.5 \\
\hline & IIL-CPs-1s26 & Dietzia timorensis ID05-A0528 ${ }^{\top}$ (AB377289) & 95.9 & 37.5 \\
\hline \multirow[t]{3}{*}{ Piezodorus guildinii } & IIL-cPg-8s3 & Mycobacterium phocaicum CIP $108542^{\top}$ (AY859682) & 96.6 & 73.3 \\
\hline & IIL-cPg-8s5 & Propionibacterium acnes KPA171202 (AE017283) & 98.8 & 13.3 \\
\hline & IIL-CPg-8s21 & Propionibacterium acnes KPA171202 ${ }^{\top}$ (AE017283) & 99.8 & 13.3 \\
\hline \multirow[t]{7}{*}{ Thyanta perditor } & IIL-cTp-5s2 & Actinomyces naes/undii NCTC $10301^{\top}$ (X81062) & 97.1 & 11.1 \\
\hline & IIL-cTp-5s4 & Corynebacterium variabile DSM $20132^{\top}$ (AJ222815) & 98.6 & 5.6 \\
\hline & IIL-cTp-5s5 & Mycobacterium phocaicum CIP $108542^{\top}$ (AY859682) & 96.4 & 44.4 \\
\hline & IIL-cTp-5s8 & Actinomyces meyeri CIP $103148^{\top}$ (X82451) & 98.6 & 5.6 \\
\hline & IIL-cTp-5s10 & Curtobacterium ginsengisoli DCY26 $6^{\top}$ (EF587758) & 92.5 & 5.6 \\
\hline & IIL-cTp-5s24 & Corynebacterium stationis LMG $21670^{\top}$ (AJ620367) & 99.4 & 11.1 \\
\hline & IIL-cTp-5s 28 & Corynebacterium variabile DSM $20132^{\top}$ (AJ222815) & 98.4 & 16.7 \\
\hline
\end{tabular}

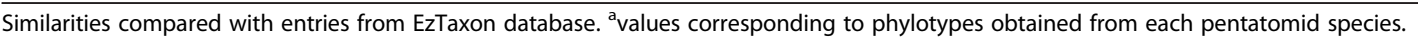

\section{Discussion}

The bacterial diversity associated with the midgut of stinkbugs has been investigated by a wide range of molecular analyses $[5,11,23,24]$, but studies addressing the actinobacteria community within pentatomids have been thoroughly neglected. The present study is the first in which selective primers for actinobacteria have been applied to survey the diversity of this bacterial group into the gastric caeca of pentatomids (Hemiptera: Pentatomidae) and revealed a rich diversity of actinobacteria inhabiting their gastric caeca.

Actinobacteria are known inhabitants of the intestinal tract of several insects, but little has been reported on their role. Termites were shown to have a fixed community of actinobacteria mostly represented by species of Actinomycetales [25], and several of the Streptomyces 


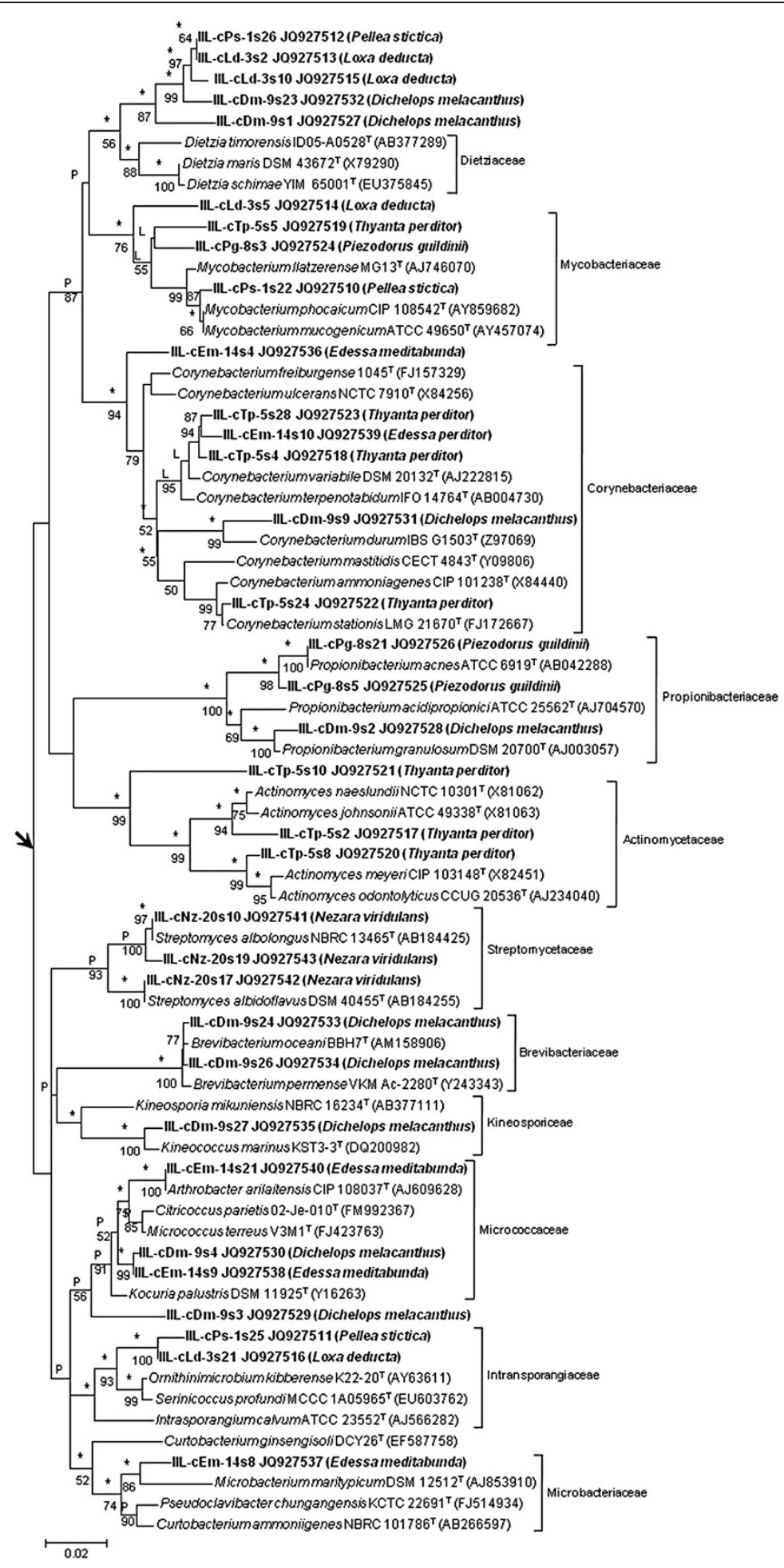

Figure 1 Neighbour-joining tree based on 16S rRNA gene sequences ( $640 \mathrm{bp})$ showing relationships between pentatomid gutassociated actinobacteria and closely free-living relatives. Asterisks indicate branches of the tree that were also recovered with the maximum-likelihood and maximum-parsimony tree-making algorithm; $L$ and $P$ indicate branches which were either recovered with the maximum-likelihood or maximum-parsimony tree-making algorithm, respectively. Numbers at the nodes are percentage bootstrap values based on 1000 resampled data sets; only values above $50 \%$ are given. The arrow indicates the inferred root position using Bacillus subtilis DSM $10^{\top}$ (GenBank accession no. AJ276351) and Escherichia coli ATCC $11775^{\top}$ (X80725) which were used as the outgroup. Bar, 0.02 substitutions per nucleotide position. 
species associated with the gut of termites have the potential to degrade hemicellulose and lignin, which are key components of the diet of these insects [14,26]. A very diverse community of actinobacteria, including species belonging to Dietzia, was also reported as gut inhabitants of scarabaeid beetles. These actinobacteria were also shown to release enzymes capable of degrading xylan and pectin as substrates [17,27]. Although these actinobacteria were show to produce a number of active enzymes that act on the food substrate of their hosts, their direct contribution to the digestive process and nutrition of their hosts has not been evaluated yet.

A number of associations among actinobacteria and hemipterans have also been reported, but far less diverse than those we report or those already described in termites and scarabaeids. Coriobacterium glomerans (Coriobacteriaceae) has been reported from the midgut of Pyrrhocoris apterus (Pyrrhocoridae) [28], and Rhodococcus rhodnii (Nocardiaceae) from the reduviids Rhodnius prolixus, Rhodnius ecuadoriensis and Triatoma infestans [2931], and Rhodococcus triatomae from Triatoma sp. [32]. Although a horizontal transmission route for C. glomerans has been recently demonstrated and molecular analysis of another pyrrhocorid species indicated the occurrence of closely related species of actinobacteria [19], gut symbionts associated with $T$. infestans and $R$. prolixus were the only ones that have been shown to play a role in host nutrition by producing vitamin B [33,34].

We do not have sufficient information to argue on the role of the actinobacteria associated with the different species of stinkbugs we have studied in here. Nonetheless, it is striking how diverse the actinoflora associated with the gastric caeca of some of these stinkbugs are as compared to others, including the species of kissing bugs. However, the same pentatomids species surveyed herein were analyzed using universal primers [11], unpub. data and none of the clones retrieved were characterized as actinobacteria. Thus, it is clear that the use of specific primers enhanced the chance to detect this special bacterial group and has, therefore, opened the opportunity to better understand the evolutionary forces which may drive the interactions between bacteria and pentatomids. Mutualistic associations with microorganisms generally occur in insects that exploit nutrient-limited food sources, and it is quite common in blood or sap-sucking hemipterans [35,36]. Blood sucking hemipterans are known to carry symbionts associated with their gut that complement the vitamin B deficiency in their natural diet [33,34], while sap-sucking hemipterans are commonly associated with symbionts housed within bacteriocytes or bacteriomes [36,37]. But there is also a number of heteropterans (Hemiptera) that are not sap or blood suckers that carry symbiont bacteria associated to their gut that affect host fitness $[38,39]$, but only one is known to be an actinobacterium $[19,28]$.
Although the reported potential of gut actinobacteria to produce enzymes to possibly aid in food processing by their hosts (termites and scarabaeids) or to synthesize nutrients (hemipterans), the well-known potential of Actinobacteria to produce bioactive metabolites has led some to argue that these bacteria may also have a more general role in host protection against the invasion of pathogenic bacteria [22]. This hypothesis has gained support by the growing body of information on the association of actinobacteria with insects, in which actinobacteria are ectopically associated with the integument of Hymenoptera to produce a plethora of antibiotics to protect their hosts or the host's food source [7,20,21,40]. Insect symbiosis have been reported more than half a century ago [35] and has regained attention due to the possible exploitation of symbionts for insect pest and/or insect-vectored disease control $[8,30,41]$ and the impact they can have on pest- and disease-control programmes [42]. However, the biotechnological potential of bacterial symbionts associated to insects is another face of insect symbioses that is seldom explored, especially the extracellular bacterial symbionts $[40,41,43,44]$.

Furthermore, most of the genera found inhabiting the midgut of the pentatomids in here studied has already been reported associated with other insects. Some of them have a beneficial impact on the insect fitness, i.e., streptomycetes in hymenopterans [20,21] and corynebacterial symbionts in Rhodnius spp. [30]. Other genera, such as Dietzia [27,45] and Brevibacterium [46], have been recently isolated from insects and the last may play a pathogenic association with their hosts [47]. The ecological features of these interactions could be achieved by selective isolation of the symbionts. However, our initial attempts to culture the actinobacteria associated with a couple of the stinkbugs we have studied by using several selective media for actinobacteria (data not shown) were fruitless so far, indicating a likely intrinsic coevolutionary relationship between these organisms or the environment (insect midgut) have selected actinobacteria species that may require special nutritional requirements.

\section{Conclusions}

Thus, it is clear that the gastric caeca of pentatomids can be considered as an untapped reservoir of putative new species of actinobacteria. The new $16 \mathrm{~S}$ rRNA gene subclade formed by the IIL-cDm-9s1 phylotype justifies any attempt to isolate and cultivate the actinoflora associated to stinkbugs. Finally, although many have sought to characterize the microbiological diversity in the stinkbug midgut, the simple use of a different primer set demonstrated the existence of a high diversity of an earlier unnoticed group of bacteria, indicating that the interactions between these insects and their symbionts are more complex than previously thought. 


\section{Methods}

\section{Insect sampling and midgut extraction}

The pentatomids Dichelops melacanthus, Nezara viridula, Edessa meditabunda, Loxa deducta, Pellaea stictica, Piezodorus guildinii and Thyanta perditor were collected in a soybean field (South of Brazil, 2008/2009) and kept under laboratory conditions on a mixed diet composed of green beans and soybean and peanut seeds. From each studied species two adult females were surface sterilized before dissection. Their midguts were dissected under a microscope and transferred to a clean glass slide. The posterior section of the midgut (V4, crypt or caeca-bearing region) was removed, washed three times in sterile phosphate-buffer saline (PBS), macerated and then subjected for DNA extraction. Dissections were carried out under sterile conditions and all tools used were autoclaved before use.

\section{S rRNA gene sequencing analysis}

The genomic DNA from the V4-midgut section of all individuals was extracted following Sunnucks and Hales [48]. The 16S rRNA gene was selectively amplified from purified genomic DNA by using primers designed for general identification of actinobacteria (S-C-Act-0235-aS-20: 5'-GGCCTATCAGCTTGTTG-3' and S-C-Act-0 878-a-A-19: 5'-CCGTACTCCCCAGGCGGGG-3') [49]. The polymerase chain reaction (PCR) mixture contained $10 \mathrm{ng}$ gDNA, $1 \mathrm{x}$ PCR buffer, $1.5 \mathrm{mM} \mathrm{MgCl}, 0.2 \mathrm{mM}$ of each deoxyribonucleoside triphosphate, $0.32 \mu \mathrm{M}$ of each primer, 0.5 U GoTaq polymerase, and sterile MilliQ $\mathrm{H}_{2} \mathrm{O}$ to $25 \mu \mathrm{L}$. PCR condition used the touchdown protocol recommended by Stach et al. [49]. The PCR product was visualized by electrophoresis in a $0.8 \%(\mathrm{w} / \mathrm{v})$ agarose gel, and the PCR product was purified using a PCR Product Purification Kit (Qiagen, USA), according to the manufacturer's instructions.

The PCR product was then cloned into the pGEMTeasy cloning vector and positive clones were selected following the manufacturer's guidelines (Promega). Plasmids of selected clones (10 per individual, two rounds of 10 clones/pentatomid species) were extracted, purified and subjected to RFLP-PCR analysis prior to sequencing. Amplicons produced with the original primer set (S-CAct-0235-a-S-20 and S-C-Act-0878-a-A-19) were subjected to restriction analysis with three informative restriction enzymes, EcoRI, MspI and SalI, and those which showed a different RFLP pattern were selected and sequenced using T7 and M13 universal primers. 16S rRNA gene sequences were compared with entries in the updated EzTaxon database [50]. The nucleotide sequences of $16 \mathrm{~S}$ rRNA gene sequences of the phylotypes have been deposited with the GenBank database under accession numbers JQ927510-JQ927543.

\section{Phylogenetic analysis}

Sequences were aligned using the MEGA4 software [51], and manually trimmed before further analysis. Phylogenetic trees were inferred by using the maximum-likelihood [52], maximum-parsimony [53] and neighbour-joining [54] tree-making algorithms drawn from the MEGA4 [51] and PHYML [55] packages. The Jukes and Cantor [56] model was used to generate evolutionary distance matrices for the neighbor-joining data. Topologies of the resultant trees were evaluated by bootstrap analysis [57] of the neighbour-joining method based upon 1,000 replicates using the MEGA4 software. Bacillus subtilis DSM $10^{\mathrm{T}}$ (GenBank accession no. AJ276351) and Escherichia coli ATCC $11775^{\mathrm{T}}$ (X80725) were used as outgroups.

\section{Authors' contributions}

TDZ, SSP and FLC planned the research. TDZ and SSP performed the cloning and RFLP analysis. TDZ carried out nucleotide sequencing and phylogenetic analysis. SSP collected the samples and revised the manuscript. TDZ and FLC wrote the manuscript. All authors read and approved the final manuscript.

\section{Acknowledgements}

Authors would like to thank Dr Antônio R. Panizzi (EMBRAPA) for providing samples of insects. The authors are in debt to FAPESP (Fundação de Amparo à Pesquisa do Estado de São Paulo) for providing fellowships to TDZ (grant 07/58712-5) and SSP (grant 09/54257-7). FLC is also thankful to FAPESP for providing the necessary funds for developing this research (grants 07/590191 and 10/50412-5).

\section{Author details}

'Lab de Microbiologia Ambiental, EMBRAPA Meio Ambiente, Rodovia SP 340, Km 127,5, CP 69, 13820-000, Jaguariúna, SP, Brazil. ²Lab de Interações em Insetos, Depto de Entomologia \& Acarologia, Escola Superior de Agricultura "Luiz de Queiroz", Universidade de São Paulo (ESALQ/USP), Av Pádua Dias 11, CP 9, 13418-900, Piracicaba, SP, Brazil. "Lab de Quarentena "Costa Lima", EMBRAPA Meio Ambiente, Rodovia SP 340, Km 127,5, CP 69, 13820-000, Jaguariúna, SP, Brazil.

Received: 6 December 2011 Accepted: 30 May 2012

Published: 8 June 2012

\section{References}

1. Grimaldi DA, Engel MS: Evolution of the insects. Cambridge U.K.: New York: Cambridge University Press; 2005

2. Saier MH Jr: Bugs. Water Air Soil Pollut 2010, 205(Suppl 1):S5-S7.

3. Douglas AE: Nutritional interactions in insect-microbial symbioses: aphids and their symbiotic bacteria Buchnera. Annu Rev Entomol 1998, 43:17-37.

4. Ohkuma M: Termite symbiotic systems: efficient bio-recycling of lignocellulose. Appl Microbiol Biotechnol 2003, 61(1):1-9.

5. Hosokawa T, Kikuchi Y, Shimada M, Fukatsu T: Obligate symbiont involved in pest status of host insect. Proc Biol Sci 2007, 274(1621):1979-1984.

Moran NA: Symbiosis. Curr Biol 2006, 16(20):R866-R871.

7. Schoenian I, Spiteller M, Ghaste M, Wirth R, Herz H, Spiteller D: Chemical basis of the synergism and antagonism in microbial communities in the nests of leaf-cutting ants. Proc Natl Acad Sci U S A 2011, 108(5):1955-1960.

8. Douglas AE: Symbiotic microorganisms: untapped resources for insect pest control. Trends Biotechnol 2007, 25(8):338-342.

9. Beard CB, Cordon-Rosales C, Durvasula RV: Bacterial symbionts of the Triatominae and their potential use in control of chagas disease transmission. Annu Rev Entomol 2002, 47:123-141.

10. Prado SS, Almeida RPP: Role of symbiotic gut bacteria in the development of Acrosternum hilare and Murgantia histrionica (Hemiptera: Pentatomidae). Entomol Exp Appl 2009, 132(1):21-29.

11. Prado SS, Almeida RPP: Phylogenetic placement of pentatomid stink bug gut symbionts. Curr Microbiol 2009, 58(1):64-69. 
12. Kikuchi Y, Hosokawa T, Nikoh N, Fukatsu T: Gut symbiotic bacteria in the cabbage bugs Eurydema rugosa and Eurydema dominulus (Heteroptera: Pentatomidae). Appl Entomol Zool 2011, 47(1):1-8.

13. Tada A, Kikuchi Y, Hosokawa T, Musolin DL, Fujisaki K, Fukatsu T: Obligate association with gut bacterial symbiont in Japanese populations of the southern green stinkbug Nezara viridula (Heteroptera: Pentatomidae). Appl Entomol Zool 2011, 46(4):483-488.

14. Schäfer A, Konrad R, Kuhnigk T, Kampfer P, Hertel H, Konig H: Hemicellulose-degrading bacteria and yeasts from the termite gut. J Appl Bacteriol 1996, 80(5):471-478.

15. Thongaram $T$, Hongoh $Y$, Kosono S, Ohkuma M, Trakulnaleamsai S, Noparatnaraporn N, Kudo T: Comparison of bacterial communities in the alkaline gut segments among various species of higher termites. Extremophiles 2005, 9(3):229-238.

16. Mohr K, Tebbe CC: Diversity and phylotype consistency of bacteria in the guts of three bee species (Apoidea) at an oilseed rape field. Envrion Microbiol 2006, 8(2):258-272.

17. Park DS, Oh H-W, Jeong W-J, Kim H, Park H-Y, Bae KS: A culture-based study of the bacterial communities within the guts of nine longicorn beetle species and their exo-enzyme producing properties for degrading xylan and pectin. J Microbiol 2007, 45(5):394-401.

18. Harington JS: Synthesis of thiamine and folic acid by Nocardia rhodnii, the micro-symbiont of Rhodnius prolixus. Nature 1960, 188:1027-1028.

19. Kaltenpoth M, Winter SA, Kleinhammer A: Localization and transmission route of Coriobacterium glomerans, the endosymbiont of pyrrhocorid bugs. FEMS Microbiol Ecol 2009, 69(3):373-383.

20. Kaltenpoth M, Goettler W, Dale C, Stubblefield JW, Herzner G, RoeserMueller K, Strohm E: 'Candidatus Streptomyces philanthi', an endosymbiotic streptomycete in the antennae of Philanthus digger wasps. Int J Syst Evol Microbiol 2006, 56(6):1403-1411.

21. Zucchi TD, Guidolin AS, Consoli FL: Isolation and characterization of actinobacteria ectosymbionts from Acromyrmex subterraneus brunneus (Hymenoptera, Formicidae). Microbiol Res 2011, 166(1):68-76.

22. Kaltenpoth M: Actinobacteria as mutualists: general healthcare for insects?. Trends Microbiol 2009, 17(12):529-535.

23. Hosokawa T, Kikuchi Y, Nikoh N, Shimada M, Fukatsu T: Strict hostsymbiont cospeciation and reductive genome evolution in insect gut bacteria. PLOS Biol 2006, 4(10):e337.

24. Kikuchi Y, Hosokawa T, Nikoh N, Meng XY, Kamagata Y, Fukatsu T: Hostsymbiont co-speciation and reductive genome evolution in gut symbiotic bacteria of acanthosomatid stinkbugs. BMC Bio/ 2009, 7:2

25. Lefebvre T, Miambi E, Pando A, Diouf M, Rouland-Lefèvre C: Gut-specific actinobacterial community structure and diversity associated with the woodfeeding termite species, Nasutitermes corniger (Motschulsky) described by nested PCR-DGGE analysis. Insectes Sociaux 2009, 56(3):269-276.

26. Pasti MB, Pometto AL 3rd, Nuti MP, Crawford DL: Lignin-solubilizing ability of actinomycetes isolated from termite (Termitidae) gut. Appl Environ Microbiol 1990, 56(7):2213-2218.

27. Takeishi H, Anzai H, Urai M, Aizawa T, Wada N, Iwabuchi N, Sunairi M, Nakajima M: Xylanolytic and alkaliphilic Dietzia sp. isolated from larvae of the Japanese horned beetle, Trypoxylus dichotomus. Actinomycetologica 2006, 20(2):49-55.

28. Haas F, König H: Coriobacterium glomerans gen. nov., sp. nov. from the intestinal tract of the red soldier bug. Int J Syst Bacterio/ 1988, 38(4):382-384

29. Hill P, Campbell JA, Petrie IA: Rhodnius prolixus and its symbiotic actinomycete: a microbiological, physiological and behavioural study. Proc R Soc Lond B Biol Sci 1976, 194(1117):501-525.

30. Durvasula RV, Sundaram RK, Kirsch P, Hurwitz I, Crawford CV, Dotson E, Beard CB: Genetic transformation of a Corynebacterial symbiont from the Chagas disease vectorTriatoma infestans. Exp Parasitol 2008, 119(1):94-98.

31. Rodríguez J, Pavía P, Montilla M, Puerta CJ: Identifying triatomine symbiont Rhodococcus rhodnii as intestinal bacteria from Rhodnius ecuadoriensis (Hemiptera: Reduviidae) laboratory insects. Int J Tropical Insect Sci 2011, 31(1-2):34-37

32. Yassin AF: Rhodococcus triatomae sp. nov., isolated from a blood-sucking bug. Int J Syst Evol Microbiol 2005, 55(4):1575-1579.

33. Baines S: The role of the symbiotic bacteria in the nutrition of Rhodnius prolixus (Hemiptera). J Exp Biol 1956, 33:533-541.

34. Eichler S, Schaub GA: The effects of aposymbiosis and of an infections with Blastocrithidia triatomae (Trypanosomatidae) on the tracheal system of the reduviid bugs Rhodnius prolixus and Triatoma infestans. J Insect Physiol 1998, 44(2):131-140.
35. Buchner P: Endosymbiosis of animals with plant microorganisms, Rev Eng edn. New York: Interscience Publishers; 1965.

36. Baumann P: Biology of bacteriocyte-associated endosymbionts of plant sap-sucking insects. Ann Rev Microbiol 2005, 59:155-189.

37. Douglas AE: Mycetocyte symbiosis in insects. Biol Rev Camb Philos Soc 1989, 64(4):409-434

38. Abe Y, Mishiro K, Takanashi M: Symbiont of brown-winged green bug, Plautia stali Scott. Japanese Journal of Applied Entomology and Zoology 1995, 39(2):109-115

39. Kikuchi Y, Hosokawa T, Fukatsu T: Insect-microbe mutualism without vertical transmission: a stinkbug acquires beneficial gut symbiont from environment every generation. Appl Environ Microbiol 2007, 73(13):4308-4316.

40. Seipke RF, Barke J, Brearley C, Hill L, Yu DW, Goss RJ, Hutchings MI: A single Streptomyces symbiont makes multiple antifungals to support the fungus farming ant Acromyrmex octospinosus. PLoS One 2011, 6(8):e22028.

41. Durvasula RV, Gumbs A, Panackal A, Kruglov O, Taneja J, Kang AS, CordonRosales C, Richards FF, Whitham RG, Beard CB: Expression of a functional antibody fragment in the gut of Rhodnius prolixus via transgenic bacterial symbiont Rhodococcus rhodnii. Med Vet Entomol 1999, 13(2):115-119.

42. Zindel R, Gottlieb Y, Aebi A: Arthropod symbioses: a neglected parameter in pest- and disease control programmes. J Appl Ecol 2011, 48(4):864-872.

43. Poulsen M, Oh DC, Clardy J, Currie CR: Chemical analyses of waspassociated Streptomyces bacteria reveal a prolific potential for natural products discovery. PLoS One 2011, 6(2):e16763.

44. Prado SS, Zucchi TD: Host-symbiont interactions for potentially managing heteropteran pests. Psyche 2012, 10:20-30.

45. Tóth EM, Hell É, Kovács G, Borsodi AK, Márialigeti K: Bacteria isolated from the different developmental stages an larval organs of the obligate parasitic fly, Wohlfahrtia magnifica (Diptera: Sarcophagidae). Microb Ecol 2006, 51(1):13-21.

46. Katı H, Ince IA, Demir İ, Demirbağ Z: Brevibacterium pityocampae sp. nov., isolated from caterpillars of Thaumetopoea pityocampa (Lepidoptera, Thaumetopoeidae). Int J Syst Evol Microbiol 2010, 60(2):312-316.

47. Selvakumar G, Sushil SN, Stanley J, Mohan M, Deol A, Rai D, Ramkewal, Bhatt JC, Gupta HS: Brevibacterium frigoritolerans a novel entomopathogen of Anomala dimidiata and Holotrichia longipennis (Scarabaeidae: Coleoptera). Biocontrol Sci Techn 2011, 21(7):821-827.

48. Sunnucks $P$, Hales DF: Numerous transposed sequences of mitochondrial cytochrome oxidase I-II in aphids of the genus Sitobion (Hemiptera: Aphididae). Mol Biol Evol 1996, 13(3):510-524.

49. Stach JE, Maldonado LA, Ward AC, Goodfellow M, Bull AT: New primers for the class Actinobacteria: application to marine and terrestrial environments. Envrion Microbiol 2003, 5(10):828-841.

50. Chun J, Lee JH, Jung Y, Kim M, Kim S, Kim BK, Lim YW: EzTaxon: a webbased tool for the identification of prokaryotes based on $16 \mathrm{~S}$ ribosomal RNA gene sequences. Int J Syst Evol Microbiol 2007, 57(10):2259-2261.

51. Tamura K, Dudley J, Nei M, Kumar S: MEGA4: Molecular Evolutionary Genetics Analysis (MEGA) software version 4.0. Mol Biol Evol 2007, 24(8):1596-1599.

52. Felsenstein J: Evolutionary trees from DNA sequences: a maximum likelihood approach. J Mol Evol 1981, 17(6):368-376.

53. Fitch WM: Toward defining the course of evolution: minimum change for specific tree topology. Syst Biol 1971, 20(4):406-416.

54. Saitou N, Nei M: The neighbour-joining method: a new method for reconstructing phylogenetic trees. Mol Biol Evol 1987, 4(4):404-425.

55. Guindon S, Gascuel O: A simple, fast, and accurate algorithm to estimate large phylogenies by maximum likelihood. Syst Biol 2003, 52(5):696-704.

56. Jukes TH, Cantor CR: Evolution of protein molecules. In Mammalian Protein Metabolism. Edited by Munro HN. New York: Academic Press; 1969:21-123.

57. Felsenstein J: Confidence limits on phylogenies: an approach using the bootstrap. Evolution 1985, 39(4):783-791.

doi:10.1186/1471-2180-12-101

Cite this article as: Zucchi et al:: The gastric caeca of pentatomids as a house for actinomycetes. BMC Microbiology 2012 12:101. 